\title{
A prática como componente curricular nas licenciaturas: uma análise da produção acadêmica de 2002 a 2018 no Brasil
}

\author{
The practice as a curricular component in the teaching \\ formation: an analysis of the academic production of 2002 to \\ 2018 in Brazil
}

\author{
Priscila Juliana da Silva ${ }^{1}$ \\ ORCID: http://orcid.org/0000-0002-1672-6143 \\ Orliney Maciel Guimarães² \\ ORCID: http://orcid.org/0000-0003-4762-4884
}

\begin{abstract}
Resumo: Este artigo tem como tema de investigação a Prática como Componente Curricular (PCC) na produção acadêmica do período de 2002 a 2018. Dessa forma, propõem-se como objetivo analisar aspectos qualitativos e quantitativos da produção acadêmica sobre a PCC a partir de resumos de 129 trabalhos levantados e disponíveis em três bases de dados: Banco de Dissertações e Teses da Capes, Portal de Periódicos Capes e Google Acadêmico. A análise priorizou a identificação das áreas das licenciaturas foco de cada estudo, o ano de sua defesa e lou publicação, o programa e universidade em que foram realizados, as revistas e eventos de publicação, os objetivos da pesquisa, a metodologia utilizada e os principais resultados. A partir dessa análise destaca-se a ausência de estudos sobre a PCC nas licenciaturas em Ciências, Filosofia, Física, História, Letras e Pedagogia, bem como poucos estudos com enfoque metodológico etnográfico e/ou de observação participante. Por sua vez, a análise dos principais resultados das pesquisas ressaltou duas lacunas nos estudos sobre a PCC que podem ser pesquisadas de forma separada ou em articulação: as condições
\end{abstract}

1 Licenciada em Pedagogia pela Pontifícia Universidade Católica do Rio Grande do Sul (2011). Mestre em Educação pela Pontifícia Universidade Católica do Paraná (2017), na linha de pesquisa de Teoria e Prática Pedagógica na Formação de Professores. Doutoranda em Educação na Universidade Federal do Paraná, na linha de pesquisa Cultura,Escola e Processos Formativos. Atualmente é Pedagoga no Instituto Federal de Santa Catarina (IFSC).

2 É doutora em Ciências pela USP/São Carlos (1997), mestre em Ciências pela USP/FFCLRP de Ribeirão Preto (1991), possui Licenciatura em Química pela Universidade Federal de Uberlândia (1988). Professora Titular da Universidade Federal do Paraná (1992-2019). Foi Coordenadora do Mestrado Profissional em Química em Rede Nacional - PROFQUI (2018-2019), coordenadora do Curso de Química da UFPR de 2014-2017, Foi coordenadora do Programa de Pós-Graduação em Educação em Ciências e em Matemática da UFPR (2010-2011) onde atuou de 2010 a 2016 orientando 13 dissertações de mestrado. Coordenou o Núcleo de Educação em Química da UFPR de 2000-2019, foi Tutora do Grupo PET-Química de 2008-2014. Atualmente é credenciada como Professora Permanente no Programa de Pós-Graduação em Educação da UFPR, na Linha de Pesquisa: Cultura, Escola e Processos Formativos em Educação. Atua na área de Educação em Ciências com interesse nos seguintes temas: Formação inicial e continuada de professores, Educação Inclusiva. Experimentação no Ensino de Ciências, Produção de Material Didático. 
de trabalho e carreira dos professores formadores e as trajetórias de vida de formação e de experiência na Educação Básica desses professores. Identificou-se também a ausência de estudas da PCC em cursos na modalidade de Educação a Distância (EAD).

Palavras-chave: Formação de Professores; Prática como Componente Curricular; Produção Acadêmica.

\begin{abstract}
This article has as a research theme the Practice as a Curricular Component (PCC) in academic production from the period 2002 to 2018 in Brazil. Thus, the objective of this study is to analyze qualitative and quantitative aspects of academic production on PCC from abstracts of 129 works collected and available in three databases: Bank of Dissertations and Theses of Capes, Portal of Periodical Capes and Google Academic. The analysis prioritized the identification of the areas of undergraduate studies that focus on each study, the year of its defense and/or publication, the program and university in which they were carried out, the journals and publication events, the research objectives, the methodology used and the main results. From this analysis we can highlight the absence of studies on the PCC in the teaching formation in Sciences, Philosophy, Physics, History, Literature and Pedagogy, as well as few studies with an ethnographic methodological approach and/or participant observation. In turn, the analysis of the main research results highlighted two shortcomings in the PCC studies that can be researched separately or in articulation: the working and career conditions of the teaching formation and the life trajectories of formation and experience in the Basic Education of these teachers. We also identified the absence of PCC studies in Distance Education (e-learning) courses. Key words: Teaching Formation; Practice as a Curricular Component; Academic Production.
\end{abstract}

\title{
1 INTRODUÇÃO
}

A formação de professores em nível superior no Brasil é fomentada pela legislação a partir de 1939 (BRASIL, 1939) com a criação da Faculdade Nacional de Filosofia que tinha como uma de suas finalidades preparar candidatos ao magistério para os níveis secundário e normal. Nessa época instituiu-se no país um modelo de formação docente denominado por Saviani (2009) de "3+1". Esse modelo é também chamado de racionalidade técnica e se organiza em 3 anos de formação específica e um ano de formação pedagógica. Esse modelo de formação pressupunha que para ser professor é necessário ter o domínio científico de uma área específica para depois aplicar esse conhecimento na prática pedagógica, ou seja, na atuação como professor.

Esse modelo passa a ser questionado a partir dos anos 1980 por diversos autores que propõem uma nova forma de pensar e fazer a formação docente. Esse novo modelo é denominado de racionalidade prática. No Brasil esse modelo é inspiração para a construção das Diretrizes para Formação de Professores de 2002 (BRASIL, 2002a) e 2015 (BRASIL, 2015). Nesses documentos surge uma nova proposta de licenciatura que estabelece para a prática o estatuto de conhecimento como forma de promover alterações estruturais nesses cursos e propõe 400 horas de Prática como Componente Curricular (PCC) que devem ser desenvolvidas ao longo de toda formação inicial do licenciando.

A obrigatoriedade de 400 horas de atividades de PCC propostas nas diretrizes (BRASIL,2002b) se insere em uma ampla discussão no campo da formação docente. Para Marcelo (1998) esse campo tem crescido quantitativamente e qualitativamente e suas preo- 
cupações de pesquisa se alteraram para questões que envolvem os conhecimentos dos professores, ou seja, como se aprende a ensinar. Nessa nova perspectiva da racionalidade prática o professor é um:

[...] sujeito reflexivo que toma a prática como ponto de partida da formação e da sua profissionalidade, ressignificando contextualmente a teoria. Assume a autoformação como princípio e a reflexão como possibilidade de desenvolvimento. Considera os contextos institucionais e sociais em que atua (CUNHA, 2013, p. 12).

A racionalidade prática permitiu que a formação de professores assumisse a partir dos anos 2000 as narrativas culturais e desenvolvimento profissional como conceitos centrais nas pesquisas. De acordo com Cunha (2013, p.12) nessa perspectiva o professor "[...] age com base nos saberes estruturais, provenientes de diferentes fontes e contextos. Constrói seus saberes a partir das múltiplas influências de formação, em cotejamento com o contexto cultural e institucional onde atua".

Considerando o histórico da formação docente no Brasil, inserir a PCC nos currículos das licenciaturas tem sido um desafio. Para compreender esse cenário de mudanças, este artigo apresenta como tema de investigação a PCC na produção acadêmica do período de 2002 a 2018. Dessa forma, objetiva-se analisar aspectos qualitativos e quantitativos da produção sobre a PCC a partir de resumos de 129 trabalhos levantados e disponíveis em três bases de dados: Banco de Dissertações e Teses da Capes, Portal de Periódicos Capes e Google Acadêmico.

\section{A PRÁTICA COMO COMPONENTE CURRICULAR NAS NORMATIVAS PARA A FORMAÇÃO DE PROFESSORES}

A PCC é proposta nas normativas para a formação docente na Resolução $n^{\circ} 02$ de 2002 (BRASIL, 2002b) que definiu as cargas horárias dos cursos de licenciatura a partir das propostas das Diretrizes Nacionais para a Formação de Professores (BRASIL, 2002a). Portanto, ficaram definidas que 400 horas devem ser organizadas em atividades de PCC ao longo de toda a formação do licenciando. O objetivo desse novo elemento é apresentado como uma estratégia de alterar o modelo de licenciatura vigente no Brasil que priorizava os conhecimentos específicos em detrimento dos conhecimentos pedagógicos, assim como a teoria em detrimento da prática (BRASIL, 2001). Esse objetivo está expresso no Parecer $n^{\circ}$ 09 de 2001 que preconiza as diretrizes para a formação docente.

Atualmente as Diretrizes para a Formação Inicial e Continuada de professores, Resolução nº 02 de 2015 (BRASIL, 2015) reafirmam às 400 horas para a PCC consolidando como seu objetivo redefinir os currículos e constituir uma identidade própria para os cursos de licenciatura. Igualmente, visualiza-se nas normativas para a formação de professores uma proposta de organização curricular baseada na profissionalização do trabalho docente 
sendo a prática uma dimensão do conhecimento que perpassa toda a formação do licenciando. Consequentemente, a PCC precisa estar presente ao longo de toda organização curricular das licenciaturas. Essa interpretação da PCC é reafirmada no Parecer $n^{\circ} 28$ de 2001 que a compreende como:

[...] uma prática que produz algo no âmbito do ensino. Sendo a prática um trabalho consciente cujas diretrizes se nutrem do Parecer 9/2001 ela terá que ser uma atividade tão flexível quanto outros pontos de apoio do processo formativo, a fim de dar conta dos múltiplos modos de ser da atividade acadêmico científica. Assim, ela deve ser planejada quando da elaboração do projeto pedagógico e seu acontecer deve se dar desde o início da duração do processo formativo e se estender ao longo de todo o seu processo. Em articulação intrínseca com o estágio supervisionado e com as atividades de trabalho acadêmico, ela concorre conjuntamente para a formação da identidade do professor como educador. (BRASIL, 2001b, p.9).

Essas definições de PCC apresentadas nas normativas pressupõe sua presença em todo processo formativo do licenciando e em articulação com estágio supervisionado em uma proposta que objetiva organizar a formação docente a partir de um modelo de profissionalização. Entretanto, dúvidas surgem no processo de construção de novas propostas curriculares nas instituições de ensino superior e em 2005 o Parecer n 15 esclarecesse algumas delas e define a PCC como:

[...] conjunto de atividades formativas que proporcionam experiências de aplicação de conhecimentos ou de desenvolvimento de procedimentos próprios ao exercício da docência. Por meio destas atividades, são colocados em uso, no âmbito do ensino, os conhecimentos, as competências e as habilidades adquiridas nas diversas atividades formativas que compõem o currículo do curso. As atividades caracterizadas como prática como componente curricular podem ser desenvolvidas como núcleo ou como parte de disciplinas ou de outras atividades formativas. Isto inclui as disciplinas de caráter prático relacionadas à formação pedagógica, mas não aquelas relacionadas aos fundamentos técnico-científicos correspondentes a uma determinada área do conhecimento. (BRASIL, 2005, p.3).

Esse parecer estabelece alguns limites e entendimentos da PCC na formação docente. Visualiza-se nesse documento que a PCC é entendida de modo distinto do estágio supervisionado, pois não depende da atuação do licenciando no espaço educativo como professor, mas sim é uma forma de articular a teoria e a prática pedagógica em todo o currículo. Logo, de acordo com essa definição é possível que as práticas sejam desenvolvidas como um núcleo específico ou como parte de disciplinas o que acaba por contradizer a primeira concepção de prática como uma dimensão do conhecimento que deve estar presente ao longo de toda formação do licenciando.

Outra contradição pode ser percebida nas normativas está presente no Parecer $\mathrm{n}^{\circ}$ 15 de 2005 que apresenta outra interpretação da PCC, não como uma dimensão do co- 
nhecimento, mas como um "[...] conjunto de atividades formativas que proporcionam experiências de aplicação de conhecimentos ou de desenvolvimento de procedimentos próprios ao exercício da docência" (BRASIL, 2005, p. 3). Esse trecho se destaca pela interpretação das práticas de PCC como aplicação. Essa visão se contradiz com a visão de prática como uma dimensão do conhecimento à medida que está relacionada a uma visão técnica da relação teoria e prática, em que se apropria primeiro da teoria para depois aplicá-la. Essa concepção está em consonância com a racionalidade técnica que é o modelo que as diretrizes buscam alterar.

Ainda, no Parecer n¹5 de 2005 (BRASIL, 2005), evidencia-se que as atividades práticas da área específica de formação do licenciando não podem ser contabilizadas como PCC estabelecendo um caráter de prática pedagógica para a PCC que vem sendo desenvolvida de diversas formas nos cursos de licenciatura.

A Resolução nº 2 de 2015, que normatiza cursos de formação de professores inicial e continuada, preconiza a articulação entre teoria e prática e a relação da instituição formadora com a Educação básica. Nessa normativa, entre os diversos objetivos do Núcleo de Aprofundamento e Diversificação do currículo da formação inicial, destaca-se que devem ser desenvolvidas "[...] atividades práticas articuladas entre os sistemas de ensino e instituições educativas de modo a propiciar vivências nas diferentes áreas do campo educacional" (BRASIL, 2015, p.11). Portanto, a PCC se estabelece nos currículos das licenciaturas como articuladora de conhecimentos promovendo alterações nas concepções e práticas de formação docente.

Real (2012) ao analisar a legislação que orienta a Prática como Componente Curricular aponta contradições entre a política nacional para a formação de professores e os diversos pareceres apresentados. Portanto, mesmo com diversas orientações os entendimentos e formas de organizar a PCC nos currículos de licenciatura dependem das interpretações que são mediadas pelos contextos e pela cultura de cada instituição. Consequentemente, compreender os estudos que têm sido realizados sobre a PCC pode nos mostrar lacunas para futuras pesquisas, bem como as potencialidades e dificuldades de pensar a prática como uma dimensão do conhecimento para além dos fins de aplicação e em relação às experiências do cotidiano escolar.

\section{METODOLOGIA}

Esta pesquisa documental sobre a PCC caracteriza-se como a fase exploratória, tal como propõe Minayo (2015), que tem a finalidade de auxiliar na delimitação do objeto de pesquisa, na definição de sua problemática, de seus instrumentos de coleta de dados e dos referenciais teóricos adotados. Assim, essa fase exploratória insere-se em uma pesquisa ampla de doutorado que está em andamento no Programa de Pós-graduação em Educação da Universidade Federal do Paraná (UFPR) que tem como objeto de estudo a PCC. 
Para realizar essa pesquisa exploratória foram considerados os passos para a realização de estudos de estado da arte propostos por Romanowski e Ens (2006) e Teixeira e Megid Neto (2017). Dessa forma as seguintes etapas foram realizadas e serão apresentadas ao longo do texto.

1. Definição de um tema/objeto/problemática.

2. Definição de descritores para busca nas bases de dados.

3. Definição do intervalo de tempo a ser considerado nas buscas nas bases de dados.

4. Definição das bases de dados a serem consultadas.

5. Definição de critérios de seleção entre os trabalhos encontrados.

6. Definição dos critérios de análise dos trabalhos.

7. Análise e avaliação dos trabalhos selecionados.

8. Escrita do relatório.

Considerou-se como objeto da busca documental a PCC. Por isso definiu-se como único descritor o termo "prática como componente curricular". Como a PCC surgiu nas diretrizes de 2002, estabeleceu-se o período de 2002 a 2018 para buscas em três bases de dados: Bancos de Dissertações e Teses da Capes; Portal de Periódicos da Capes; Google Acadêmico.

No Banco de Dissertações e Teses da Capes foram encontrados um total de 55 trabalhos. No Portal de Periódicos da Capes foram encontrados um total de 37 trabalhos, mas somente 16 foram selecionados para análise, pois os demais não têm relação com o objeto de estudo deste artigo. Por sua vez no Google Acadêmico a busca encontrou 98 trabalhos, entretanto foram eliminados da análise trabalhos já identificados nas demais bases de dados pesquisadas (33) e planejamentos de atividades de PCC de uma universidade (7). Portanto, para análise de publicações encontradas no Google Acadêmico considerou-se o total de 58 trabalhos. Totaliza-se 129 trabalhos encontrados sobre a Prática como Componente Curricular nas três bases de dados que tiveram seus resumos analisados. Destaca-se que 10 trabalhos não foram analisados em todos os critérios definidos, pois não tinham seus resumos disponíveis.

Realizou-se uma análise dos resumos de todos os trabalhos encontrados considerando-se critérios quantitativos e qualitativos. Desse modo, foram analisados nesses resumos os seguintes critérios: as áreas das licenciaturas foco do estudo, o ano de defesa e / ou publicação, o programa e universidade em que foram realizados, as revistas e eventos de publicação, os objetivos da pesquisa, metodologia e os principais resultados. Esses dados foram organizados em dois arquivos. O primeiro com todos os resumos de todos os trabalhos no qual se realizou a análise qualitativa dos objetivos, metodologia, referenciais e conclusões. O segundo de abordagem quantitativa que auxiliou na organização das tabelas e gráficos. 


\section{ANÁLISE DA PRODUÇÃO ACADÊMICA SOBRE A PRÁTICA COMO COMPONEN- TE CURRICULAR}

Com o objetivo de identificar os 129 trabalhos analisados neste artigo apresentam-se abaixo dois quadros. O quadro 1 apresenta as dissertações e teses identificando seus títulos, tipo de trabalho e ano de publicação.

\section{Quadro 1 - Dissertações e Teses Analisadas}

\begin{tabular}{|c|c|c|}
\hline TÍTULO DO TRABALHO & TIPO & ANO \\
\hline $\begin{array}{l}\text { A construção das competências pedagógicas através da prática como compo- } \\
\text { nente curricular na formação inicial em Educação Física }\end{array}$ & Dissertação & 2005 \\
\hline $\begin{array}{l}\text { A prática como componente curricular: um estudo em cursos de Licenciatura } \\
\text { em Matemática }\end{array}$ & Dissertação & 2005 \\
\hline $\begin{array}{l}\text { A prática nos cursos de licenciatura: reestruturação curricular da formação ini- } \\
\text { cial }\end{array}$ & Tese & 2006 \\
\hline $\begin{array}{l}\text { Prática docente de estagiários de Educação Física após a resolução 07/2004: } \\
\text { a dicotomia teoria-prática }\end{array}$ & Dissertação & 2008 \\
\hline $\begin{array}{l}\text { As inter-relações entre universidade e escola básica: o estágio e a prática de } \\
\text { futuros professores das séries iniciais na construção de conhecimentos peda- } \\
\text { gógicos da Matemática }\end{array}$ & Dissertação & 2008 \\
\hline $\begin{array}{l}\text { Reformulação curricular no curso de Licenciatura em Química: fatores que } \\
\text { contribuem para a configuração de um processo inovador }\end{array}$ & Dissertação & 2009 \\
\hline $\begin{array}{l}\text { Propostas de formação inicial de professores de Matemática: um estudo de } \\
\text { projetos político-pedagógicos de cursos no estado do Paraná }\end{array}$ & Dissertação & 2009 \\
\hline Prática pedagógica como componente curricular formativo: uma etnografia & Dissertação & 2009 \\
\hline $\begin{array}{l}\text { O futuro professor de Matemática e o processo de identificação com a profis- } \\
\text { são docente: um estudo sobre as contribuições da prática como componente } \\
\text { curricular }\end{array}$ & Dissertação & 2010 \\
\hline $\begin{array}{l}\text { Formação de professores de Educação Física: limites, contradições, e possibi- } \\
\text { lidades da prática como componente curricular }\end{array}$ & Dissertação & 2010 \\
\hline $\begin{array}{l}\text { Possibilidades para a articulação entre teoria e prática em cursos de licencia- } \\
\text { tura }\end{array}$ & Dissertação & 2010 \\
\hline $\begin{array}{l}\text { Práxis e a noção de prática nos documentos oficiais sobre a formação de pro- } \\
\text { fessores }\end{array}$ & Dissertação & 2010 \\
\hline $\begin{array}{l}\text { Perfil dos cursos de formação de professores dos programas de licenciatura } \\
\text { em química das instituições públicas de ensino superior da região nordeste do } \\
\text { país }\end{array}$ & Tese & 2010 \\
\hline A formação de profissionais de História: o caso da UFRN $(2004-2008)$ & Dissertação & 2010 \\
\hline $\begin{array}{l}\text { Atividade física adaptada no contexto das matrizes curriculares dos cursos de } \\
\text { Educação Física }\end{array}$ & Tese & 2010 \\
\hline $\begin{array}{l}\text { A prática como componente curricular na Universidade Federal do Maranhão: } \\
\text { implicações no curso de Licenciatura em Educação Física }\end{array}$ & Dissertação & 2011 \\
\hline $\begin{array}{l}\text { Formação inicial de professores de Química na região norte: análise das dife- } \\
\text { rentes concepções das IES públicas e de professores e estudantes do ensino } \\
\text { médio }\end{array}$ & Tese & 2011 \\
\hline $\begin{array}{l}\text { A prática como componente curricular nos cursos de Licenciatura em Matemá- } \\
\text { tica: entendimentos e alternativas para sua incorporação e desenvolvimento }\end{array}$ & Dissertação & 2012 \\
\hline
\end{tabular}




\begin{tabular}{|c|c|c|}
\hline $\begin{array}{l}\text { A prática como componente curricular em projetos pedagógicos de cursos de } \\
\text { Licenciatura em Matemática }\end{array}$ & Tese & 2012 \\
\hline $\begin{array}{l}\text { Políticas curriculares para formação de professores de Química: a prática } \\
\text { como componente curricular em questão }\end{array}$ & Dissertação & 2012 \\
\hline $\begin{array}{l}\text { Estágio curricular obrigatório e prática como componente curricular nos cursos } \\
\text { de licenciatura da UNIPLAC: que prática é essa?' }\end{array}$ & Dissertação & 2012 \\
\hline $\begin{array}{l}\text { A dimensão prática na preparação profissional em Educação Física: concep- } \\
\text { ção e organização acadêmica }\end{array}$ & Tese & 2012 \\
\hline O portfólio na formação reflexiva de professores de Educação Física & Dissertação & 2012 \\
\hline $\begin{array}{l}\text { Processo de estudo de temas matemáticos relativos ao ensino fundamental, } \\
\text { por intermédio de situação-problema: práticas vivenciadas por acadêmicos do } \\
\text { curso de Licenciatura em Matemática }\end{array}$ & Tese & 2012 \\
\hline $\begin{array}{l}\text { A relação entre as práticas de formação de professores e a teoria do conheci- } \\
\text { mento no curso de Licenciatura em Educação Física da Universidade Regional } \\
\text { do Cariri }\end{array}$ & Tese & 2012 \\
\hline $\begin{array}{l}\text { A prática como componente curricular na formação de professores do curso de } \\
\text { Licenciatura em Biologia do IFPI campus Floriano }\end{array}$ & Dissertação & 2013 \\
\hline $\begin{array}{l}\text { A prática como componente curricular na formação do professor de Biologia: } \\
\text { contribuições? }\end{array}$ & Dissertação & 2013 \\
\hline $\begin{array}{l}\text { Um estudo sobre as configurações curriculares e potenciais formativos de cur- } \\
\text { sos de Licenciatura em Física do estado de Minas Gerais }\end{array}$ & Tese & 2013 \\
\hline $\begin{array}{l}\text { A prática como componente curricular da Licenciatura em Matemática: suges- } \\
\text { tões de professores da educação básica }\end{array}$ & Dissertação & 2014 \\
\hline $\begin{array}{l}\text { Licenciatura em Matemática a distância na modalidade online: um estudo so- } \\
\text { bre um curso da Universidade Aberta do Brasil }\end{array}$ & Tese & 2014 \\
\hline $\begin{array}{l}\text { As práticas pedagógicas e os saberes da docência na formação acadêmico- } \\
\text {-profissional em Ciências Biológicas }\end{array}$ & Tese & 2014 \\
\hline $\begin{array}{l}\text { A atividade orientadora de ensino como alternativa metodológica para a abor- } \\
\text { dagem de metais pesados na disciplina de química analítica qualitativa }\end{array}$ & Dissertação & 2014 \\
\hline $\begin{array}{l}\text { Formação de professores do curso de Educação Física da UEPA: a inclusão } \\
\text { escolar de pessoas com deficiência }\end{array}$ & Dissertação & 2014 \\
\hline $\begin{array}{l}\text { Hibridição epistemológica e formativa na Licenciatura em Ciências Biológicas: } \\
\text { um estudo de contrastes sobre a implicação dos professores universitários de } \\
\text { disciplinas específicas }\end{array}$ & Tese & 2014 \\
\hline $\begin{array}{l}\text { Construção de relações teoria-prática na formação de professores de Ciências } \\
\text { e Biologia }\end{array}$ & Tese & 2014 \\
\hline $\begin{array}{l}\text { A prática como componente curricular na perspectiva da formação inicial do } \\
\text { professor de Geografia para a educação básica }\end{array}$ & Dissertação & 2015 \\
\hline $\begin{array}{l}\text { A prática pedagógica como componente curricular na formação de professo- } \\
\text { res: a visão de graduandos do curso de Ciências Biológicas (diurno) da Univer- } \\
\text { sidade Federal de Santa Catarina }\end{array}$ & Dissertação & 2015 \\
\hline $\begin{array}{l}\text { Sentidos da prática como componente curricular na Licenciatura em Ciências } \\
\text { Biológicas }\end{array}$ & Dissertação & 2015 \\
\hline $\begin{array}{l}\text { Análise dos aspectos pedagógicos da formação do professor de Educação } \\
\text { Física: um estudo nas IES públicas de Minas Gerais }\end{array}$ & Dissertação & 2015 \\
\hline $\begin{array}{l}\text { Formação inicial de professores e a integração da prática como componente } \\
\text { curricular na disciplina de matemática elementar }\end{array}$ & Tese & 2015 \\
\hline $\begin{array}{l}\text { A prática como componente curricular em Licenciaturas de Letras: um estudo } \\
\text { discursivo das relações entre teoria e prática }\end{array}$ & Dissertação & 2015 \\
\hline $\begin{array}{l}\text { Entre as práticas das teorias e vice-versa: a prática de ensino como compo- } \\
\text { nente curricular nas Licenciaturas em História no brasil após } 2002\end{array}$ & Tese & 2015 \\
\hline $\begin{array}{l}\text { Laboratório de ensino de matemática: uma proposta matemática para licencia- } \\
\text { tura em e a utilização de jogos de recorrência }\end{array}$ & Dissertação & 2015 \\
\hline
\end{tabular}




\begin{tabular}{|c|c|c|}
\hline $\begin{array}{l}\text { Iniciando a docência: a construção do perfil profissional na visão dos futuros } \\
\text { professores de Ciências da UFPEL }\end{array}$ & Dissertação & 2015 \\
\hline $\begin{array}{l}\text { A formação do professor de Geografia na UFSC: concepção sobre o processo } \\
\text { formativo }\end{array}$ & Dissertação & 2015 \\
\hline $\begin{array}{l}\text { A prática como componente curricular nos cursos de formação de professores } \\
\text { de Química no estado de Goiás }\end{array}$ & Dissertação & 2016 \\
\hline $\begin{array}{l}\text { Configurações da prática como componente curricular nos cursos de Licencia- } \\
\text { tura em Ciências Biológicas de universidades públicas em Goiás: sentidos e } \\
\text { implicações }\end{array}$ & Dissertação & 2016 \\
\hline $\begin{array}{l}\text { Entre concepções e desafios: a prática pedagógica como componente curricu- } \\
\text { lar na perspectiva de professores universitários de Ciências Biológicas }\end{array}$ & Dissertação & 2016 \\
\hline $\begin{array}{l}\text { A prática como componente curricular na formação inicial do professor de Ma- } \\
\text { temática: um olhar na perspectiva da legislação brasileira }\end{array}$ & Dissertação & 2016 \\
\hline Jogos didáticos na formação inicial de professores de Biologia & Dissertação & 2016 \\
\hline $\begin{array}{l}\text { A prática como componente curricular via projeto integrado de prática educati- } \\
\text { va (PIPE) no ensino de estatística na universidade: implementação e implica- } \\
\text { ções na formação inicial do professor de Matemática }\end{array}$ & Tese & 2016 \\
\hline $\begin{array}{l}\text { A configuração da prática como componente curricular nos cursos de Licencia- } \\
\text { tura em Ciências Biológicas das universidades estaduais da Bahia }\end{array}$ & Tese & 2016 \\
\hline $\begin{array}{l}\text { Teoria e prática no processo de formação profissional: o caso de um curso de } \\
\text { Licenciatura em Matemática }\end{array}$ & Tese & 2016 \\
\hline $\begin{array}{l}\text { Constituição da identidade profissional docente dos formadores de professo- } \\
\text { res de Biologia: potencialidades da intercoletividade }\end{array}$ & Tese & 2016 \\
\hline $\begin{array}{l}\text { Os estudos ciência, tecnologia e sociedade e a prática como componente cur- } \\
\text { ricular: tensões, desafios e possibilidades na formação de professores nas } \\
\text { Ciências Biológicas. }\end{array}$ & Tese & 2016 \\
\hline $\begin{array}{l}\text { A prática como componente curricular e o estágio supervisionado na concep- } \\
\text { ção dos licenciandos: entre o texto e o contexto }\end{array}$ & Dissertação & 2017 \\
\hline $\begin{array}{l}\text { O contexto de formação a partir da exploração de um caso multimídia: apren- } \\
\text { dizagens de futuros professores de Matemática }\end{array}$ & Tese & 2017 \\
\hline $\begin{array}{l}\text { Prática como componente curricular - definições legais e sua expressão na } \\
\text { formação inicial do professor de Ciências e Biologia }\end{array}$ & Dissertação & 2017 \\
\hline $\begin{array}{l}\text { Formação de professores de Matemática: a proposta integradora da prática } \\
\text { como componente curricular no IFFAR }\end{array}$ & Tese & 2017 \\
\hline A prática como componente curricular na formação de professores de Geografia & Dissertação & 2018 \\
\hline
\end{tabular}

Fonte: Organizado pelas autoras a partir de dados do Banco de Dissertações e Teses da Capes e Google Acadêmico.

O quadro 2 abaixo apresenta os títulos, os tipos de trabalho e ano de publicação dos artigos, eventos, relatórios de pesquisa e trabalhos de conclusão de curso analisados.

Quadro 2 - Artigos, eventos, trabalhos de conclusão de curso de relatórios de pesquisa analisados

\begin{tabular}{|l|c|c|}
\hline \multicolumn{1}{|c|}{ Título do trabalho } & Tipo & ANO \\
\hline As questões da prática pedagógica como componente curricular nas licenciaturas & Evento & 2005 \\
\hline $\begin{array}{l}\text { A prática como componente curricular: uma possibilidade de inovação ou uma } \\
\text { re-semantização retórica na discussão curricular dos cursos de formação de } \\
\text { professores? }\end{array}$ & Artigo & 2005 \\
\hline
\end{tabular}




\begin{tabular}{|c|c|c|}
\hline $\begin{array}{l}\text { A organização da prática como componente curricular em cursos de Licencia- } \\
\text { tura em Ciências Biológicas }\end{array}$ & Evento & 2008 \\
\hline $\begin{array}{l}\text { A prática como componente curricular no curso de Licenciatura em Educação } \\
\text { Física da Universidade Regional do Cariri - campus de Iguatu: um retrato da } \\
\text { sua realidade }\end{array}$ & Evento & 2010 \\
\hline $\begin{array}{l}\text { Prática como componente curricular e sua implementação em sala de aula na } \\
\text { visão de formadores de um curso de Letras }\end{array}$ & Artigo & 2011 \\
\hline $\begin{array}{l}\text { A prática como componente curricular na Licenciatura em Matemática: múlti- } \\
\text { plos contextos, saberes e sujeitos }\end{array}$ & Artigo & 2011 \\
\hline $\begin{array}{l}\text { Desafios da formação de professores de Língua Portuguesa: a relação entre os } \\
\text { saberes disciplinares e os saberes da prática }\end{array}$ & Artigo & 2011 \\
\hline A prática como componente curricular na formação de professores & Artigo & 2011 \\
\hline $\begin{array}{l}\text { A prática como componente curricular na Licenciatura em Matemática: múlti- } \\
\text { plos contextos, saberes e sujeitos }\end{array}$ & Artigo & 2011 \\
\hline $\begin{array}{l}\text { Conteúdos das disciplinas de interface atribuídos à prática como componente } \\
\text { curricular }\end{array}$ & Artigo & 2012 \\
\hline $\begin{array}{l}\text { Prática como componente curricular: uma proposta para a Licenciatura em } \\
\text { Matemática }\end{array}$ & Evento & 2012 \\
\hline A prática como componente curricular: o que isso significa na prática? & Artigo & 2012 \\
\hline Prática como componente curricular: o que é isso? & Evento & 2012 \\
\hline $\begin{array}{l}\text { A prática como componente curricular na formação de professores: a visão dos } \\
\text { licenciandos de Ciências Biológicas da UFSCAR - Sorocaba }\end{array}$ & Evento & 2012 \\
\hline $\begin{array}{l}\text { Conteúdos das disciplinas de interface atribuídos à prática como componente } \\
\text { curricular }\end{array}$ & Artigo & 2012 \\
\hline $\begin{array}{l}\text { Mil horas para quê? A prática como componente curricular na Licenciatura em } \\
\text { História }\end{array}$ & Artigo & 2013 \\
\hline $\begin{array}{l}\text { Concepção de alunos e professores sobre a prática como componente curricu- } \\
\text { lar no curso de formação de professores de Ciências e Biologia }\end{array}$ & Artigo & 2013 \\
\hline $\begin{array}{l}\text { A prática como componente curricular: entendimentos da comunidade discipli- } \\
\text { nar de educadores químicos }\end{array}$ & Evento & 2013 \\
\hline $\begin{array}{l}\text { A prática como componente curricular nos cursos de Licenciaturas em Ciên- } \\
\text { cias e Biologia }\end{array}$ & $\begin{array}{l}\text { Relatório de } \\
\text { pesquisa }\end{array}$ & 2013 \\
\hline $\begin{array}{l}\text { A prática como componente curricular no processo de formação inicial: na prá- } \\
\text { tica a teoria é outra? }\end{array}$ & Evento & 2013 \\
\hline $\begin{array}{l}\text { A prática como componente curricular nos cursos de formação de professores: } \\
\text { reflexões compartilhadas }\end{array}$ & Artigo & 2013 \\
\hline $\begin{array}{l}\text { Iniciação a docência em Matemática: propostas e constituição de saberes na } \\
\text { prática como componente curricular }\end{array}$ & Evento & 2013 \\
\hline $\begin{array}{l}\text { A prática como componente curricular em disciplinas específicas e pedagógi- } \\
\text { cas em um curso de Licenciatura em Ciências Biológicas }\end{array}$ & Evento & 2013 \\
\hline $\begin{array}{l}\text { A prática como componente curricular na formação do professor de Biologia: } \\
\text { avanços e desafios na UFRPE }\end{array}$ & Artigo & 2014 \\
\hline $\begin{array}{l}\text { Prática como componente curricular e o estágio supervisionado na formação } \\
\text { do professor de Educação Física }\end{array}$ & Artigo & 2014 \\
\hline Prática como componente curricular: questões e reflexões & Artigo & 2014 \\
\hline $\begin{array}{l}\text { Prática como componente curricular (PCC) nas Licenciaturas em Ciências Bio- } \\
\text { lógicas: espaço/tempo de aprendizagem profissional? }\end{array}$ & Artigo & 2014 \\
\hline $\begin{array}{l}\text { A prática como componente curricular na formação de professores do curso } \\
\text { de Licenciatura em Biologia do IFPI campus Floriano: subsídios de inovação }\end{array}$ & Artigo & 2014 \\
\hline $\begin{array}{l}\text { Práticas de ensino e formação docente: notas sobre a experiência da Licencia- } \\
\text { tura em Filosofia da UFABC }\end{array}$ & Artigo & 2015 \\
\hline
\end{tabular}




\begin{tabular}{|c|c|c|}
\hline $\begin{array}{l}\text { Relações teoria-prática na formação de professores de Ciências: um estudo das } \\
\text { interações discursivas no interior de uma disciplina acadêmica }\end{array}$ & Artigo & 2015 \\
\hline $\begin{array}{l}\text { Prática como componente curricular: entre tradições e novidades no currículo } \\
\text { da formação de professores nas Ciências Biológicas }\end{array}$ & Evento & 2015 \\
\hline $\begin{array}{l}\text { Uma análise da natureza dos trabalhos sobre a prática como componente cur- } \\
\text { ricular: dissertações e teses 2011-2012 }\end{array}$ & Evento & 2015 \\
\hline $\begin{array}{l}\text { A prática como componente curricular no curso de formação de professores de } \\
\text { Biologia: algumas possibilidades }\end{array}$ & Evento & 2015 \\
\hline $\begin{array}{l}\text { A realidade da inserção da prática como componente curricular em Licenciatu- } \\
\text { ra em Química no estado de Goiás. }\end{array}$ & Evento & 2015 \\
\hline $\begin{array}{l}\text { Da grade à concepção: a prática como componente curricular nos cursos de } \\
\text { Licenciatura em História da UNEB e UEFS }\end{array}$ & Evento & 2015 \\
\hline $\begin{array}{l}\text { As possibilidades e desafios para a implementação da prática como compo- } \\
\text { nente curricular em currículos de formação de professores }\end{array}$ & Artigo & 2015 \\
\hline $\begin{array}{l}\text { A prática como componente curricular na formação inicial de professores de } \\
\text { Matemática: o caso da licenciatura na Universidade Tecnológica Federal do } \\
\text { Paraná }\end{array}$ & Evento & 2015 \\
\hline $\begin{array}{l}\text { Prática como componente curricular nas disciplinas de língua da habilitação } \\
\text { em Letras/Alemão: alguma novidade? }\end{array}$ & Evento & 2016 \\
\hline Sem título & Artigo & 2016 \\
\hline $\begin{array}{l}\text { A prática como componente curricular na Licenciatura em Física da Universi- } \\
\text { dade Estadual de Ponta Grossa }\end{array}$ & Evento & 2016 \\
\hline $\begin{array}{l}\text { A prática como componente curricular no projeto pedagógico de uma Licencia- } \\
\text { tura em Matemática }\end{array}$ & Evento & 2016 \\
\hline $\begin{array}{l}\text { A prática como componente curricular na licenciatura em Matemática da Uni- } \\
\text { versidade Estadual de Mato Grosso do Sul }\end{array}$ & Evento & 2016 \\
\hline $\begin{array}{l}\text { Prática como componente curricular: uma análise de suas diferentes formas } \\
\text { nos projetos pedagógicos de licenciaturas de cursos na área das Ciências } \\
\text { Naturais da Universidade Federal de Santa Catarina }\end{array}$ & $\begin{array}{l}\text { Trabalho de con- } \\
\text { clusão de curso }\end{array}$ & 2016 \\
\hline $\begin{array}{l}\text { A prática como componente curricular nos cursos de Licenciatura em Matemá- } \\
\text { tica do IFSP }\end{array}$ & Artigo & 2017 \\
\hline $\begin{array}{l}\text { Uma visão sobre a prática como componente curricular utilizando oficinas pe- } \\
\text { dagógicas e recursos midiáticos no ensino de Química }\end{array}$ & Artigo & 2017 \\
\hline $\begin{array}{l}\text { A Universidade Federal do Sul da Bahia (UFSB) e o projeto universidade nova: } \\
\text { como ficam as licenciaturas? }\end{array}$ & Artigo & 2017 \\
\hline $\begin{array}{l}\text { Prática como componente curricular como elemento formativo: compreensões } \\
\text { nos projetos pedagógicos de Licenciatura em Química em Goiás. }\end{array}$ & Artigo & 2017 \\
\hline $\begin{array}{l}\text { Os desafios da operacionalização da prática como componente curricular no } \\
\text { curso de Licenciatura em Geografia da UNICENTRO - campus de Irati - Pa- } \\
\text { raná, Brasil }\end{array}$ & Artigo & 2017 \\
\hline $\begin{array}{l}\text { A prática como componente curricular na Licenciatura em Matemática: o que } \\
\text { é? }\end{array}$ & Artigo & 2017 \\
\hline $\begin{array}{l}\text { A prática como componente curricular na Universidade Federal da Bahia: pos- } \\
\text { sibilidades do trato com o conhecimento }\end{array}$ & Evento & 2017 \\
\hline $\begin{array}{l}\text { A prática como componente curricular nos cursos de Licenciatura em Ciências } \\
\text { Biológicas de Goiás: relação teoria-prática }\end{array}$ & Evento & 2017 \\
\hline $\begin{array}{l}\text { Configuração da prática como componente curricular nos cursos de Química } \\
\text { da UFGD }\end{array}$ & Artigo & 2017 \\
\hline $\begin{array}{l}\text { A percepção de licenciandos sobre a prática como componente curricular na } \\
\text { formação inicial em Ciências Biológicas }\end{array}$ & Evento & 2017 \\
\hline $\begin{array}{l}\text { Circulação de sentidos da prática como componente curricular na Licenciatura } \\
\text { em Ciências Biológicas }\end{array}$ & Artigo & 2017 \\
\hline
\end{tabular}




\begin{tabular}{|l|c|c|}
\hline $\begin{array}{l}\text { Formação de professores de Química em instituições estaduais baianas: um } \\
\text { olhar para a prática como componente curricular }\end{array}$ & Evento & 2017 \\
\hline $\begin{array}{l}\text { A prática como componente curricular em um curso de Licenciatura em Mate- } \\
\text { mática da UTFPR: uma análise na perspectiva da teoria da atividade }\end{array}$ & Artigo & 2017 \\
\hline Prática como componente curricular: entendimentos, possibilidades e perspectivas & Artigo & 2018 \\
\hline $\begin{array}{l}\text { A prática como componente curricular e o estágio supervisionado na concep- } \\
\text { ção dos licenciandos: entre o texto e o contexto }\end{array}$ & Artigo & 2018 \\
\hline $\begin{array}{l}\text { A prática como componente curricular na formação inicial de professores de } \\
\text { Educação Física }\end{array}$ & Artigo & 2018 \\
\hline $\begin{array}{l}\text { Um panorama de pesquisas sobre a prática como componente curricular na } \\
\text { Licenciatura em Matemática }\end{array}$ & Artigo & 2018 \\
\hline $\begin{array}{l}\text { Matriz curricular e a organização da prática como componente curricular: qua- } \\
\text { dro atual e perspectivas }\end{array}$ & Evento & 2018 \\
\hline $\begin{array}{l}\text { Formação de professores na UFGD: análise do estágio obrigatório e da prática } \\
\text { como componente curricular no curso de Letras }\end{array}$ & Evento & 2018 \\
\hline $\begin{array}{l}\text { Operacionalização da prática como componente curricular nos cursos de li- } \\
\text { cenciatura em Geografia: estudo de caso de três universidades públicas do } \\
\text { Paraná }\end{array}$ & Artigo & 2018 \\
\hline $\begin{array}{l}\text { A prática como componente curricular e a escolha pela licenciatura nos cursos } \\
\text { diurnos de Ciências Biológicas da UFSC }\end{array}$ & $\begin{array}{l}\text { Trabalho de con- } \\
\text { clusão de curso }\end{array}$ & 2018 \\
\hline $\begin{array}{l}\text { A prática como componente curricular em um curso de Pedagogia a distância: } \\
\text { formação de professores surdos em foco }\end{array}$ & Evento & 2018 \\
\hline $\begin{array}{l}\text { Prática como componente curricular em um curso de Licenciatura em Matemá- } \\
\text { tica: uma análise à luz da teoria da atividade }\end{array}$ & Artigo & 2018 \\
\hline $\begin{array}{l}\text { A prática como componente curricular na disciplina de ensino de Língua Portu- } \\
\text { guesa auxiliando a formação do pedagogo }\end{array}$ & Evento & 2018 \\
\hline $\begin{array}{l}\text { A prática como componente curricular no contexto das políticas e da formação } \\
\text { docente em Geografia }\end{array}$ & Artigo \\
\hline $\begin{array}{l}\text { Reflexões sobre a prática como componente curricular do curso de Licenciatu- } \\
\text { ra em Educação Física da Universidade Federal do Maranhão }\end{array}$ & Artigo & 2018 \\
\hline
\end{tabular}

Fonte: Organizado pelas autoras a partir de dados do Portal de Periódicos da Capes e Google Acadêmico.

Ao analisar a distribuição desses 129 trabalhos identificados acima, que tratam sobre a PCC, ao longo dos anos, visualiza-se na tabela 1 que os primeiros trabalhos aparecem em 2005 embora a resolução que normatiza a PCC seja de 2002. Percebe-se que ao longo dos anos o número de trabalhos vem crescendo consideravelmente na mesma medida em que a PCC vai se constituindo de diversas formas nas licenciaturas. Destacam-se os anos de 2015, 2016 e 2017 que apresentam o maior número de trabalhos.

Tabela 1 - Números de Trabalhos sobre PCC de 2005 a 2018 por Base de Dados

\begin{tabular}{|c|c|c|c|c|c|c|c|c|c|c|c|c|c|c|c|}
\hline \multirow{2}{*}{$\begin{array}{l}\text { ANO/BASE DE } \\
\text { DADOS }\end{array}$} & \multirow{2}{*}{ 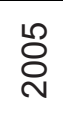 } & \multirow{2}{*}{ 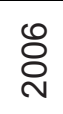 } & \multirow{2}{*}{ 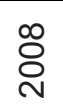 } & \multirow{2}{*}{$\stackrel{\text { \& }}{\circ}$} & \multirow{2}{*}{ 웅 } & \multirow{2}{*}{$\overline{\check{N}}$} & \multirow{2}{*}{$\stackrel{N}{\check{N}}$} & \multirow{2}{*}{ 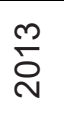 } & \multirow{2}{*}{$\stackrel{+}{\sim}$} & \multirow{2}{*}{$\stackrel{L}{\stackrel{2}{N}}$} & \multirow{2}{*}{$\stackrel{\circ}{\stackrel{N}{N}}$} & \multirow{2}{*}{$\stackrel{N}{\sim}$} & \multirow{2}{*}{$\stackrel{\infty}{\infty}$} & \multicolumn{2}{|c|}{ TOTAL } \\
\hline & & & & & & & & & & & & & & $\mathrm{N}^{\circ}$ & $\%$ \\
\hline $\begin{array}{l}\text { Google Acadê- } \\
\text { mico }\end{array}$ & 2 & 0 & 1 & 1 & 1 & 1 & 4 & 6 & 3 & 7 & 9 & 12 & 11 & 58 & 44,9 \\
\hline $\begin{array}{l}\text { Banco de } \\
\text { Dissertações e } \\
\text { Teses Capes }\end{array}$ & 2 & 1 & 2 & 2 & 7 & 2 & 8 & 3 & 7 & 10 & 9 & 2 & 0 & 55 & 42,6 \\
\hline
\end{tabular}




\begin{tabular}{|l|c|c|c|c|c|c|c|c|c|c|c|c|c|c|c|}
\hline $\begin{array}{l}\text { Portal de Perió- } \\
\text { dicos Capes }\end{array}$ & 0 & 0 & 0 & 0 & 0 & 3 & 1 & 2 & 2 & 2 & 0 & 3 & 3 & 16 & 12,4 \\
\hline TOTAL & 4 & 1 & 3 & 3 & 8 & 6 & 13 & 11 & 12 & 19 & 18 & 17 & 14 & 129 & 100,00 \\
\hline
\end{tabular}

Fonte: Organizada pelas autoras a partir de dados do Banco de Teses e Dissertações da Capes, Portal de Periódicos da Capes e Google Acadêmico.

Esses 129 trabalhos apresentados na tabela 1 foram classificados em 6 categorias. $\mathrm{Na}$ categoria artigo foram encontrados 36 trabalhos que totalizam 27,91\% do total. Na categoria Dissertação 39 trabalhos foram incluídos e totalizam 30,23\% do total. Foram identificados 29 trabalhos de eventos que totalizam $22,48 \%$ do total e 22 teses que totalizam $17,05 \%$ do total. Por sua vez as menores incidências foram de relatório de pesquisa e de trabalho de conclusão de curso representando $2,33 \%$ dos trabalhos.

As categorias de trabalhos classificados como 'dissertações' e 'teses' foram analisadas a partir das universidades e dos programas de pós-graduação ao qual se vinculam. Em vista disso, a tabela 2 apresenta o número de dissertações e teses por área do programa de pós-graduação. Nessa tabela destacam-se como os principais fomentadores de estudos sobre a PCC os programas de pós-graduação em Educação, com 20 trabalhos que representam 32,79\% do total, e em Educação em Ciências e Matemática, com 17 trabalhos que representam $27,87 \%$ do total. Considerando que os programas de pós-graduação em Educação em Ciências e em Educação Científica e Tecnológica são afins ao programa de Educação em Ciências e Matemática pode-se inferir que a área de ensino de Ciências e Matemática supera a da Educação em estudos sobre a PCC.

Tabela 2 - Dissertações e Teses por Área de Concentração do Programa de Pós-graduação

\begin{tabular}{|l|l|l|l|l|}
\hline \multirow{2}{*}{ PROGRAMA DE PÓS-GRADUAÇÃO } & \multirow{2}{*}{ DISSERTAÇÃO } & \multirow{2}{*}{ TESE } & \multicolumn{2}{|l|}{ TOTAL GERAL } \\
\cline { 4 - 6 } & & & $N^{\circ}$ & $\%$ \\
\hline Educação & 12 & 8 & 20 & 32,79 \\
\hline Educação em Ciências e Matemática & 11 & 6 & 17 & 27,87 \\
\hline Educação Científica e Tecnológica & 3 & 3 & 6 & 9,84 \\
\hline Química & 3 & 2 & 5 & 8,20 \\
\hline Educação em Ciências & 3 & 1 & 4 & 6,56 \\
\hline Educação Especial & 0 & 1 & 1 & 1,64 \\
\hline Educação Física & 3 & 1 & 4 & 6,56 \\
\hline Geografia & 2 & 0 & 2 & 3,28 \\
\hline História & 1 & 0 & 1 & 1,64 \\
\hline Letras & 1 & 0 & 1 & 1,64 \\
\hline TOTAL GERAL & 39 & 22 & 61 & 100,00 \\
\hline
\end{tabular}

Fonte: Organizada pelas autoras a partir de dados do Banco de Teses e Dissertações da Capes. 
Em relação às universidades as quais os trabalhos se vinculam, muitas instituições são apontadas, mas em sua maioria tem apenas um ou dois trabalhos sobre a PCC. Por isso optou-se por destacar apenas as instituições com maiores números de trabalho.

Nesse contexto a UFSC se destaca com 10 trabalhos que em sua maioria estão vinculados ao Programa de Pós-Graduação em Educação Científica e Tecnológica e tem como principal objeto de estudo a Licenciatura em Biologia. Outras instituições que se destacam são a PUC-SP com 5 trabalhos que em sua maioria discute a PCC no curso de Licenciatura em Matemática, a Unesp com 5 trabalhos e a UFG e a UFSCAR com 4 trabalhos cada.

Na categoria de trabalho 'artigos' foram identificados 35 trabalhos sobre a PCC publicados em 30 revistas. Em números, a maioria das revistas tem um ou dois artigos publicados. Entretanto destaca-se que a maioria das revistas tem um enfoque de formação específica, ou seja, o 'ensino de...' e publicaram artigos sobre a PCC vinculada às licenciaturas de seu enfoque. Por outro lado, as revistas de formação de professores e/ou de foco na educação publicam artigos que tratam da PCC como política curricular.

$\mathrm{Na}$ categoria de trabalho 'eventos' foram identificados 29 trabalhos publicados em 21 eventos diferentes. Entre os diferentes eventos destaca-se o Encontro Nacional de Pesquisa em Educação Em Ciências (ENPEC) com 6 publicações. Além disso, verifica-se que apesar dos eventos terem entre um e dois trabalhos sobre PCC publicados, entre os 21 eventos 9 tem como foco o ensino de Ciências ou Matemática totalizando 16 trabalhos publicados. Novamente destaca-se a área de ensino de Ciências ou Matemática como fomentadores dos trabalhos sobre PCC.

Com relação aos cursos em que os estudos sobre PCC foram realizados, apresenta-se a tabela 3. Nessa tabela visualiza-se que os três cursos com maior incidência de trabalhos são: 1) Matemática, com 30 trabalhos; 2) Biologia, com 29 trabalhos; 3) Química, com 15 trabalhos.

$\mathrm{Na}$ tabela 3 foram considerados os trabalhos que analisam a PCC como política educacional para a formação de professores sem enfocar um curso específico. Esses trabalhos representam $7,75 \%$ do total, sendo em sua maioria artigos publicados em revistas.

Tabela 3 - Trabalhos sobre PCC por Curso/Temática de Análise

\begin{tabular}{l|c|c}
\hline \multirow{2}{*}{ Base de Dados } & \multicolumn{2}{|c}{ TRABALHOS } \\
\cline { 2 - 3 } & $\mathrm{N}^{\circ}$ & $\%$ \\
\hline Matemática & 30 & 23,26 \\
\hline Biologia & 29 & 22,48 \\
\hline Química & 15 & 11,63 \\
\hline Educação Física & 14 & 10,85 \\
\hline $\begin{array}{l}\text { Políticas para formação do- } \\
\text { cente }\end{array}$ & 10 & 7,75 \\
\hline Geografia & 7 & 5,43 \\
\hline Letras & 5 & 3,88 \\
\hline
\end{tabular}




\begin{tabular}{l|l|l}
\hline Ciências & 4 & 3,10 \\
\hline História & 4 & 3,10 \\
\hline Diversos cursos & 3 & 2,33 \\
\hline Física & 3 & 2,33 \\
\hline Pedagogia & 3 & 2,33 \\
\hline Filosofia & 1 & 0,78 \\
\hline Interdisciplinar & 1 & 0,78 \\
\hline TOTAL GERAL & 129 & 100,00 \\
\hline
\end{tabular}

Fonte: Organizada pelas autoras a partir de dados do Banco de Teses e Dissertações da Capes, Portal de Periódicos da Capes e Google Acadêmico.

A partir dos resumos dos 129 trabalhos realizou-se a classificação de cada pesquisa de acordo com a sua natureza. Portanto, na tabela 4 é possível visualizar que as pesquisas de campo, documental e bibliográfica são as que aparecem com maior incidência. Destaca-se que 10 resumos dos 129 trabalhos não foram identificados e 4 trabalhos com resumos disponíveis não apresentam dados que permitam classificar a natureza da pesquisa. Dessa forma, foram analisados dentro desse critério 115 trabalhos. Com menores incidências foram classificados 4 trabalhos como 'Relato de experiência' e 1 trabalho como 'Pesquisa-ação'. Os relatos de experiências são textos que analisam situações didáticas específicas consideradas como PCC em um determinado curso de licenciatura. Já o estudo identificado como pesquisa-ação se coloca nessa categoria em seu resumo.

Tabela 4 - Natureza da pesquisa nos trabalhos sobre PCC

\begin{tabular}{l|l|l}
\hline NATUREZA DA PESQUISA & $\mathrm{N}^{\circ}$ & $\%$ \\
\hline Pesquisa de campo & 46 & 40 \\
Pesquisa documental & 45 & 39,13 \\
Pesquisa bibliográfica & 11 & 9,57 \\
Pesquisa etnográfica & 8 & 6,96 \\
Relato de experiência & 4 & 3,48 \\
Pesquisa-ação & 1 & 0,87 \\
\hline TOTAL & 115 & 100 \\
\hline
\end{tabular}

Fonte: Organizada pelas autoras a partir de dados do Banco de Teses e Dissertações da Capes, Portal de Periódicos da Capes e Google Acadêmico.

Ainda sobre os dados da tabela 4, ao realizar essa classificação considerou-se 'Pesquisa de campo' todos os estudos que realizam a triangulação de dados empíricos e utilizam instrumentos de coleta de dados que consideram os sujeitos que vivenciam as atividades de PCC. Sendo assim, esses estudos se utilizam de questionários entrevistas, grupos focais e em muitos casos articulam seus dados à análise de documentos com PPC e regulamentos internos das instituições. 
Os estudos classificados como 'Pesquisa documental' tem como único enfoque os Projetos Pedagógicos de Curso (PPC) e regulamentos das instituições que organizam a PCC. Por sua vez, os estudos denominados 'Pesquisa bibliográfica' se diferenciam dos estudos de 'Pesquisa documental' por apresentar reflexões teóricas que articulam as diretrizes para a formação docente com diferentes autores que discutem temáticas relacionadas à licenciatura.

Com menores incidências foram classificados 8 trabalhos de 'Pesquisa etnográfica'. Esses trabalhos se caracterizam por realizar estudos em que o pesquisador se inseriu em uma instituição e buscou analisar a PCC a partir de observações. Desses 8 trabalhos apenas dois se denominam etnográficos no resumo, os demais foram assim classificados, pois definem em sua metodologia de coleta de dados e análise o uso de observações e cadernos de campo.

$\mathrm{Na}$ análise qualitativa dos resumos dos trabalhos foi possível elaborar a tabela 5 e 6 que apresentam as frequências nos resumos das metodologias de coleta e de análise de dados. Dos 129 trabalhos encontrados sobre a PCC foram excluídos da análise dos instrumentos de coleta de dados 10 trabalhos sem resumos, bem como 14 que não apresentavam informações sobre esse critério. Já na análise das formas de análise de dados foram excluídos os 10 trabalhos sem resumo e 84 trabalhos que não apresentaram esse critério.

Com relação às formas de coleta de dados foram identificadas 152 citações sendo as maiores frequências distribuídas entre a análise documental $(48,03 \%)$, a entrevista $(27,63 \%)$ e o questionário $(16,45 \%)$. Com menor incidência destaca-se a observação participante $(7,89 \%)$ e grupo focal $(2,63 \%)$. Entretanto grupos focais podem ser considerados uma modalidade de entrevista coletiva e em alguns trabalhos foram utilizadas juntamente com outras estratégias de coleta de dados.

Tabela 5 - Instrumentos de Coleta de Dados nos Trabalhos sobre PCC

\begin{tabular}{l|c|c|c|c|c|c}
\hline Sigla do trabalho & $\begin{array}{c}\text { Análise } \\
\text { documental }\end{array}$ & Entrevista & Questionário & $\begin{array}{c}\text { Observação } \\
\text { participante }\end{array}$ & $\begin{array}{c}\text { Grupo } \\
\text { focal }\end{array}$ & TOTAL \\
\hline Dissertação 1 & 1 & 1 & 0 & 1 & 1 & 4 \\
Dissertação 10 & 1 & 1 & 1 & 0 & 1 & 4 \\
Evento 10 & 1 & 1 & 1 & 0 & 1 & 4 \\
Dissertação 8 & 1 & 1 & 1 & 0 & 0 & 3 \\
Tese 4 & 1 & 1 & 1 & 0 & 0 & 3 \\
Tese 6 & 1 & 1 & 1 & 0 & 0 & 3 \\
Dissertação 25 & 1 & 1 & 1 & 0 & 0 & 3 \\
Dissertação 26 & 1 & 1 & 1 & 0 & 0 & 3 \\
Tese 11 & 1 & 1 & 1 & 0 & 0 & 3 \\
Dissertação 32 & 1 & 1 & 1 & 0 & 0 & 3 \\
Tese 15 & 1 & 1 & 0 & 1 & 0 & 3 \\
Artigo 1 & 1 & 2 & 0 & 0 & 0 & 3 \\
Artigo 5 & 1 & 1 & 1 & 0 & 0 & 3 \\
Tese 21 & 1 & 1 & 1 & 0 & 0 & 3
\end{tabular}




\begin{tabular}{|c|c|c|c|c|c|}
\hline Evento 18 & 1 & 1 & 1 & 0 & 0 \\
\hline Evento 23 & 1 & 1 & 0 & 1 & 0 \\
\hline Dissertação 37 & 1 & 1 & 1 & 0 & 0 \\
\hline Tese 10 & 1 & 1 & 1 & 0 & 0 \\
\hline Dissertação 5 & 1 & 0 & 1 & 0 & 0 \\
\hline Dissertação 6 & 1 & 1 & 0 & 0 & 0 \\
\hline Dissertação 9 & 0 & 0 & 1 & 1 & 0 \\
\hline Dissertação 13 & 1 & 0 & 1 & 0 & 0 \\
\hline Dissertação 14 & 1 & 1 & 0 & 0 & 0 \\
\hline Dissertação 15 & 1 & 1 & 0 & 0 & 0 \\
\hline Dissertação 16 & 1 & 1 & 0 & 0 & 0 \\
\hline Dissertação 17 & 1 & 1 & 0 & 0 & 0 \\
\hline Tese 7 & 1 & 1 & 0 & 0 & 0 \\
\hline Dissertação 18 & 0 & 1 & 1 & 0 & 0 \\
\hline Dissertação 23 & 1 & 1 & 0 & 0 & 0 \\
\hline Tese 9 & 1 & 0 & 1 & 0 & 0 \\
\hline Tese 10 & 1 & 1 & 0 & 0 & 0 \\
\hline Dissertação 29 & 1 & 1 & 0 & 0 & 0 \\
\hline Tese 12 & 0 & 0 & 1 & 1 & 0 \\
\hline Tese 13 & 1 & 1 & 0 & 0 & 0 \\
\hline Tese 17 & 1 & 1 & 0 & 0 & 0 \\
\hline Tese 18 & 1 & 0 & 1 & 0 & 0 \\
\hline Tese 19 & 1 & 1 & 0 & 0 & 0 \\
\hline Dissertação 35 & 0 & 1 & 1 & 0 & 0 \\
\hline Artigo 9 & 0 & 1 & 1 & 0 & 0 \\
\hline Evento 1 & 1 & 1 & 0 & 0 & 0 \\
\hline $\begin{array}{l}\text { Relatório de pesqui- } \\
\text { sa } 1\end{array}$ & 1 & 1 & 0 & 0 & 0 \\
\hline Evento 24 & 1 & 1 & 0 & 0 & 0 \\
\hline Artigo 34 & 1 & 1 & 0 & 0 & 0 \\
\hline Dissertação 38 & 1 & 0 & 0 & 1 & 0 \\
\hline Artigo 36 & 1 & 1 & 0 & 0 & 0 \\
\hline Dissertação 2 & 1 & 0 & 0 & 0 & 0 \\
\hline Dissertação 3 & 1 & 0 & 0 & 0 & 0 \\
\hline Dissertação 4 & 0 & 1 & 0 & 0 & 0 \\
\hline Dissertação 7 & 1 & 0 & 0 & 0 & 0 \\
\hline Dissertação 12 & 1 & 0 & 0 & 0 & 0 \\
\hline Dissertação 20 & 1 & 0 & 0 & 0 & 0 \\
\hline Dissertação 24 & 0 & 0 & 0 & 1 & 0 \\
\hline Tese 8 & 1 & 0 & 0 & 0 & 0 \\
\hline Dissertação 30 & 1 & 0 & 0 & 0 & 0 \\
\hline Dissertação 31 & 1 & 0 & 0 & 0 & 0 \\
\hline Tese 16 & 0 & 0 & 0 & 1 & 0 \\
\hline Dissertação 34 & 0 & 0 & 0 & 1 & 0 \\
\hline Tese 20 & 0 & 1 & 0 & 0 & 0 \\
\hline Artigo 3 & 1 & 0 & 0 & 0 & 0 \\
\hline Artigo 4 & 0 & 0 & 1 & 0 & 0 \\
\hline
\end{tabular}




\begin{tabular}{l|c|c|c|c|c|c} 
Artigo 6 & 0 & 0 & 0 & 1 & 0 & 1 \\
Artigo 7 & 1 & 0 & 0 & 0 & 0 & 1 \\
Artigo 11 & 1 & 0 & 0 & 0 & 0 & 1 \\
Artigo 12 & 0 & 1 & 0 & 0 & 0 & 1 \\
Artigo 16 & 0 & 0 & 0 & 1 & 0 & 1 \\
Evento 2 & 1 & 0 & 0 & 0 & 0 & 1 \\
Evento 3 & 1 & 0 & 0 & 0 & 0 & 1 \\
Artigo 19 & 1 & 0 & 0 & 0 & 0 & 1 \\
Artigo 21 & 1 & 0 & 0 & 0 & 0 & 1 \\
Dissertação 36 & 1 & 0 & 0 & 0 & 0 & 1 \\
Artigo 22 & 1 & 0 & 0 & 0 & 0 & 1 \\
Evento 6 & 1 & 0 & 0 & 0 & 0 & 1 \\
Evento 8 & 1 & 0 & 0 & 0 & 0 & 1 \\
Artigo 23 & 1 & 0 & 0 & 0 & 0 & 1 \\
Evento 9 & 1 & 0 & 0 & 0 & 0 & 1 \\
Evento 11 & 1 & 0 & 0 & 0 & 0 & 1 \\
Evento 12 & 1 & 0 & 0 & 0 & 0 & 1 \\
Evento 13 & 1 & 0 & 0 & 0 & 0 & 1 \\
Evento 14 & 1 & 0 & 0 & 0 & 0 & 1 \\
Artigo 27 & 1 & 0 & 0 & 0 & 0 & 1 \\
Artigo 28 & 1 & 0 & 0 & 0 & 0 & 1 \\
Artigo 29 & 1 & 0 & 0 & 0 & 1 \\
Evento 17 & 1 & 0 & 0 & 1 & 0 & 1 \\
Artigo 30 & 0 & 0 & 0 & 0 & 1 \\
Evento 20 & 0 & 0 & 0 & 0 & 1 \\
Artigo 32 & 0 & 0 & 0 & 0 & 1 \\
Evento 22 & 0 & 0 & 0 & 1 \\
Artigo 33 & 0 & 0 & 0 & 1 \\
Artigo 35 & 0 & 0 & 0 & 0 & 1 \\
TCC2 & 0 & 0 & 0 & 2,63 & 100,00 \\
\hline TOTAL & 0 & 0 & 0 & 0 & 0 \\
\hline & 0 & 0 & 0 & 0 & 0 \\
\hline
\end{tabular}

Fonte: Organizada pelas autoras a partir de dados do Banco de Teses e Dissertações da Capes, Portal de Periódicos da Capes e Google Acadêmico.

Ao analisar o número de instrumentos de coleta de dados utilizado por cada um dos trabalhos analisados visualiza-se que 54 trabalhos utilizam 2 instrumentos (35,53\%), 45 trabalhos $(29,61 \%)$ utilizam apenas um, 45 trabalhos $(29,61 \%)$ utilizam 3 instrumentos e 8 trabalhos utilizam 4 (5,26\%).

Por sua vez, em relação às metodologias de análise dos dados (Tabela 6) identificaram-se cinco formas em 34 trabalhos. A primeira com maior frequência é a análise de conteúdo (52,95\%), seguida da análise textual discursiva (26,47\%) e logo após a análise do discurso $(14,71 \%)$. Com duas incidências identificou-se o método dialético $(5,88 \%)$ e com uma incidência a análise do discurso do sujeito coletivo (2,94\%). 
Tabela 6 - Metodologias de Análise de Dados nos Trabalhos sobre PCC

\begin{tabular}{|c|c|c|c|c|c|c|}
\hline Sigla do trabalho & $\begin{array}{l}\text { Análise de } \\
\text { Conteúdo }\end{array}$ & $\begin{array}{l}\text { Análise Tex- } \\
\text { tual Discur- } \\
\text { siva }\end{array}$ & $\begin{array}{l}\text { Análise do } \\
\text { Discurso }\end{array}$ & \begin{tabular}{|l} 
Método \\
Dialético
\end{tabular} & \begin{tabular}{|l|} 
Discurso \\
do Sujeito \\
Coletivo
\end{tabular} & TOTAL \\
\hline Tese 1 & 0 & 0 & 1 & 0 & 0 & 1 \\
\hline Dissertação 2 & 0 & 1 & 0 & 0 & 0 & 1 \\
\hline Dissertação 3 & 1 & 0 & 0 & 0 & 0 & 1 \\
\hline Dissertação 4 & 1 & 0 & 0 & 0 & 0 & 1 \\
\hline Dissertação 10 & 0 & 0 & 1 & 0 & 0 & 1 \\
\hline Tese 4 & 0 & 1 & 0 & 0 & 0 & 1 \\
\hline Dissertação 14 & 1 & 0 & 0 & 0 & 0 & 1 \\
\hline Dissertação 16 & 0 & 1 & 0 & 0 & 0 & 1 \\
\hline Dissertação 20 & 0 & 0 & 1 & 0 & 0 & 1 \\
\hline Dissertação 23 & 1 & 0 & 0 & 0 & 0 & 1 \\
\hline Dissertação 24 & 0 & 0 & 0 & 1 & 0 & 1 \\
\hline Dissertação 25 & 1 & 0 & 0 & 0 & 0 & 1 \\
\hline Tese 8 & 1 & 0 & 0 & 0 & 0 & 1 \\
\hline Tese 10 & 0 & 0 & 1 & 0 & 0 & 1 \\
\hline Tese 11 & 1 & 0 & 0 & 0 & 0 & 1 \\
\hline Dissertação 32 & 1 & 0 & 0 & 0 & 0 & 1 \\
\hline Tese 15 & 1 & 0 & 0 & 0 & 0 & 1 \\
\hline Dissertação 34 & 1 & 0 & 0 & 0 & 0 & 1 \\
\hline Tese 20 & 0 & 1 & 0 & 0 & 0 & 1 \\
\hline Artigo 5 & 0 & 0 & 0 & 0 & 1 & 1 \\
\hline Artigo 6 & 0 & 1 & 0 & 0 & 0 & 1 \\
\hline Artigo 10 & 1 & 0 & 0 & 0 & 0 & 1 \\
\hline Artigo 12 & 1 & 0 & 0 & 0 & 0 & 1 \\
\hline Evento 1 & 0 & 1 & 0 & 0 & 0 & 1 \\
\hline Artigo 21 & 0 & 1 & 0 & 0 & 0 & 1 \\
\hline Dissertação 36 & 1 & 0 & 0 & 0 & 0 & 1 \\
\hline Artigo 22 & 1 & 0 & 0 & 0 & 0 & 1 \\
\hline Relatório de pesquisa 1 & 1 & 0 & 0 & 0 & 0 & 1 \\
\hline Tese 21 & 1 & 0 & 0 & 0 & 0 & 1 \\
\hline Evento 11 & 1 & 0 & 0 & 0 & 0 & 1 \\
\hline Artigo 27 & 1 & 0 & 0 & 0 & 0 & 1 \\
\hline Evento 18 & 0 & 0 & 1 & 0 & 0 & 1 \\
\hline Evento 22 & 0 & 1 & 0 & 0 & 0 & 1 \\
\hline Evento 23 & 0 & 0 & 0 & 1 & 0 & 1 \\
\hline TCC 2 & 0 & 1 & 0 & 0 & 0 & 1 \\
\hline \multirow{2}{*}{ Total } & 18 & 9 & 5 & 2 & 1 & 34 \\
\hline & 52,94 & 26,47 & 14,71 & 5,88 & 2,94 & 100 \\
\hline
\end{tabular}

Fonte: Organizada pelas autoras a partir de dados do Banco de Teses e Dissertações da Capes, Portal de Periódicos da Capes e Google Acadêmico. 
Ao categorizar os objetivos de pesquisa propostos pelos 129 trabalhos foi possível encontrar 93 citações distribuídas em três unidades de análise. Essas unidades foram denominadas: 1) Currículo e Políticas para Formação docente (64\%); 2) Práticas (24\%); 3) Relação teoria e prática (12\%).

A unidade de análise denominada 'Currículo/Políticas para Formação docente' tem a maior frequência com 59 marcações ao longo dos resumos. Essa unidade de análise se caracteriza por apresentar nos objetivos de pesquisa sobre PCC o foco de análise em aspectos formais da estrutura curricular, nas diretrizes para formação docente, nas articulações e distinções entre estágio obrigatório e PCC e, por fim, os conhecimentos priorizados nos Projetos Pedagógicos de Curso (PPC) no planejamento das atividades de PCC. Desse modo, perpassa essa unidade de análise os aspectos formais e estruturais da PCC assumidas em diferentes cursos de licenciatura. Essas características podem ser visualizas nos trechos de resumos transcritos abaixo:

Dissertação 1: [...]objetivou investigar a prática pedagógica na forma de componente curricular do Curso de Licenciatura em Biologia do IFPI campus Floriano, postulando verificar o delineamento dessas $400 \mathrm{~h}$ de PCC no projeto pedagógico do curso [...].

Dissertação 20: [...]investigar, a partir das reformas das licenciaturas nas universidades, ocorrida em 2001, a constituição do eixo disciplinar Prática como Componente Curricular (PCC) nos currículos de licenciatura de cursos de Letras, Português/Espanhol da região sudeste brasileira [...].

Tese 4: [...]investigar a constituição da prática como componente curricular e do estágio supervisionado como espaços para o desenvolvimento da capacidade reflexiva dos saberes pedagógicos na formação acadêmico-profissional de professores em Ciências Biológicas.

Dissertação 16: [...] analisar como as práticas entendidas como componentes curriculares (PCC) estão distribuídas nas estruturas curriculares dos Projetos Pedagógicos de Curso [...].

Artigo 3: [...] descrever qualitativamente quais conteúdos são considerados nas disciplinas de interface associadas à carga horária de Prática como Componente Curricular [...].

Dentro da perspectiva da unidade de análise denominada 'Prática' foram identificadas 22 citações. Nesses trabalhos o enfoque dos estudos visa compreender a PCC a partir de experiências de sala de aula. Dessa forma, as citações abaixo mostram que esses trabalhos discutem experiências específicas em sala de aula em disciplinas que tem sua carga horária voltada para o desenvolvimento de atividades de PCC. Na primeira citação as atividades são da disciplina de Química Analítica Quantitativa, no curso de Licenciatura em Química. Já a segunda citação é de uma experiência de PCC do curso de Licenciatura em Matemática: 
Dissertação 24: Desta forma, elaborou-se uma Atividade Orientadora de Ensino (AOE) sobre os grupos analíticos IV e V, que haviam sido retirados da marcha analítica e nesta dissertação o objetivo foi investigar a potencialidade da AOE como estratégia de ensino-aprendizagem em QAQ.

Relato de Experiência I: O objetivo principal deste artigo é apresentar relatos de experiências sobre a prática como componente curricular introduzida na disciplina Introdução à Análise do curso de Licenciatura em Matemática do Instituto de Matemática e Estatística da USP (IME/USP), bem como algumas reflexões sobre o ensino de Análise Real nos cursos de formação inicial de professores.

A unidade de análise 'Relação teoria e prática' tem 12 citações. Nas citações abaixo é possível verificar a preocupação dos trabalhos em investigar como a PCC contribuiu ou não para a articulação entre teoria e prática.

Tese 16: Nosso estudo teve o objetivo de compreender os processos de construção de relações teoria-prática na formação de professores nas Ciências Biológicas.

Dissertação 18: Investiga-se a prática como componente curricular e se sua inclusão tem contribuído para a superação da dicotomia entre teoria e prática no Curso de Licenciatura em Educação Física da UFMA.

Dissertação 3: [...] compreender como a relação teoria-prática se apresenta na constituição da PCC no interior dos cursos de Licenciatura em Ciências Biológicas.

Ao categorizar os principais resultados das pesquisas realizadas e registradas nos resumos dos 129 trabalhos foram identificadas 86 citações. Ao classificar essas citações visualizaram-se duas categorias: Possibilidades da PCC para a Formação Inicial de Professores $(60,47 \%)$ e Dificuldades de implementação da PCC na Formação Inicial de Professores $(39,53 \%)$. Em cada uma dessas categorias identificaram-se unidades de análise conforme descrição da tabela 7.

Tabela 7 - Categorias organizadas a partir dos principais resultados dos trabalhos analisados

\begin{tabular}{l|l|l}
\hline POSSIBILIDADES DA PCC PARA A FORMAÇÃO INICIAL DE PROFESSORES & $N^{\circ}$ & $\%$ \\
\hline Distintos Modelos Curriculares de PCC & 15 & 17,44 \\
Promove a Relação Teoria-Prática & 9 & 10,47 \\
Mudança Curricular na Formação de Professores & 8 & 9,30 \\
Atende as Normativas para Formação Docente & 7 & 8,14 \\
Promove Integração do Trabalho Docente & 4 & 4,65 \\
Promove a Transposição Didática & 3 & 3,49 \\
Promove a Iniciação à Docência & 2 & 2,33 \\
Promove a Relação Universidade-Educação Básica & 2 & 2,33 \\
Promove a Interdisciplinaridade & 1 & 1,16 \\
Promove a Pesquisa na/sobre Docência & 1 & 1,16 \\
\hline TOTAL & 52 & 60,47 \\
\hline DIFICULDADES DE IMPLEMENTAÇÃO NA FORMAÇÃO INICIAL DE PROFESSORES & $\mathrm{N}^{\circ}$ & $\%$ \\
\hline
\end{tabular}




\begin{tabular}{l|l|l}
\hline Incompreensões da PCC & 21 & 24,42 \\
Condições de Trabalho e Carreira & 5 & 5,81 \\
Manutenção Modelo Racionalidade Técnica & 4 & 4,65 \\
Dificuldade em Promover a Relação Teoria-Prática & 3 & 3,49 \\
Ausência de PCC & 1 & 1,16 \\
\hline TOTAL & 34 & 39,53 \\
\hline
\end{tabular}

Fonte: Organizada pelas autoras a partir de dados do Banco de Teses e Dissertações da Capes, Portal de Periódicos da Capes e Google Acadêmico.

Neste conjunto de unidades de análise que compõe a categoria 'Possibilidades da PCC para a Formação Inicial de Professores', a unidade de análise 'Distintos Modelos Curriculares de PCC' representa 17\% das citações e se evidencia nos diversos trabalhos que as organizações curriculares da PCC se caracterizam pela pluralidade. Portanto, incluiu-se essa unidade de análise nessa categoria, pois se compreende que essa pluralidade expressa as articulações entre as normativas para a formação de professores, as realidades locais e a cultura de cada instituição. Esse entendimento é reforçado por Mohr e Wielewicki (2017). Entretanto os autores colocam uma ressalva importante, pois pluralidade não quer dizer que tudo pode, pois a PCC tem fundamentos e objetivos explicitados nas diretrizes para a formação docente.

São exemplos dessa unidade de análise 'Distintos Modelos Curriculares de PCC' as citações abaixo:

Dissertação 2: A partir da análise realizada, observou-se que às 400 horas de PCC não são aproveitadas da mesma maneira pelos diferentes cursos, e, em algumas propostas, nota-se que as referidas horas não são consideradas para desenvolvimento de atividades referentes à formação docente.

Dissertação 10: Em relação aos documentos institucionais, os resultados sinalizam que o modo como a PCC vem sendo inserida nos currículos de licenciatura em Ciências Biológicas caminham em várias linhas, existindo uma heterogeneidade de formas de implementação.

Artigo 16: O que se constatou é que há diferentes formas de se implementar a carga horária de prática como componente curricular (PCC), prevista nas diretrizes: a) em diferentes disciplinas; b) de modo interdisciplinar; c) em disciplinas específicas.

Nas unidades de análise que formam um conjunto que se inicia com a palavra 'Promove' são destaques importantes as possibilidades de mudanças de concepções e práticas sobre currículo; formação e aprendizagem que a implementação das atividades de PCC pode fomentar nos cursos de licenciatura. Pelo mesmo motivo destaca-se a unidade de análise 'Mudança Curricular na Formação de Professores'. Dessa forma, os trechos dos trabalhos a seguir exemplificam essas possibilidades de maior articulação entre teoria e prática e entre os diferentes conhecimentos que compõe o currículo da formação docente nas licenciaturas: 
Dissertação 7: [...] a articulação teoria e prática mostrou-se central na formação, evidenciando o desafio de na licenciatura promover atividades formativas profissionais que possibilitem aprender Matemática nos conteúdos das Ciências Humanas e Sociais, bem como aprender sobre sociedade, humanidade, ética, por exemplo, no conteúdo das ciências exatas, tendo em vista o formar-se para formar o outro: o aluno da educação básica.

Dissertação 16: Entendemos que o curso, ao fazer uma proposta de se trabalhar via projetos articuladores, estimulou uma postura reflexiva, questionadora e de trabalho coletivo no ambiente escolar, propiciado pela inserção e implementação da PCC.

Tese 21: Como resultados da investigação constatamos que (i) a proposta integradora da PCC mobiliza uma reorganização diferente do processo de formação de professores de Matemática do IFFar: uma reorganização que (ii) traz consequências às ações da gestão dos cursos, bem como (iii) requisita outras ações pedagógicas aos formadores. Por isso, evidencia-se a emergência de um paradigma diferente do convencionalmente realizado no processo de formação de professores.

A unidade de análise 'Atende as Normativas para Formação Docente' representa 8,14\% e está presente, especialmente, em estudos de análise documental. Dessa forma, esses estudos identificam que os PPC e regulamentos das instituições estão atendendo as normativas para formação docente definindo a PCC.

Neste conjunto de unidades de análise que compõe a categoria 'Possibilidades da PCC para a Formação Inicial de Professores' visualiza-se, a partir da baixa incidência de alguns pressupostos para a formação de professores preconizados nas normativas (BRASIL, 2015), a necessidade de se encontrar caminhos para promover na formação docente, pela PCC, a interdisciplinaridade, relação teoria e prática e relação instituição formadora com Educação Básica.

No conjunto de unidades de análise que compõe a categoria 'Dificuldades de implementação da PCC na Formação Inicial de Professores', a unidade de análise 'Incompreensões da PCC' representa $24 \%$ das citações. Na análise qualitativa dessa unidade de análise percebe-se que em algumas citações com a frase explícita de incompreensão da PCC como destacado abaixo na Tese 1. Em outras citações se apresenta como a necessidade de reorganizar a PCC devido as suas contradições. Outros trabalhos mostram uma distância entre a forma de organizar PCC nos cursos e as normativas para a formação de professores, ou seja, enfatizam a distancia entre o escrito nos PPC para a realização da PCC e o realizado em sala de aula ou no desconhecimento de licenciandos sobre essa prática. Ainda se percebe, como no Artigo 11, a dificuldade de estabelecer as distinções entre PCC e Estágio Supervisionado:

Tese 1: [...] mostra intenção em atualizar a dimensão prática no currículo, dificultada, de outro lado, por certa incompreensão quanto à natureza dessa prática enquanto componente curricular e quanto ao modo pelo qual realizá-la [...]

Dissertação 5: Os resultados permitiram compreender que há lacuna entre aquilo que a legislação prescreve e o que, de fato, ocorre na prática em relação à PCC. Os 
professores formadores e os licenciandos demonstram algumas fragilidades sobre o significado da PCC.

Artigo 2: Naqueles cursos em que foi possível ter acesso a essas informações, o levantamento sobre como a carga horária de PCC está contemplada mostrou que esse é um espaço que ainda gera dúvidas para aqueles que construíram os PPP dos cursos. Isso porque em praticamente metade deles o espaço do PCC nos currículos não estava claro.

Artigo 11: Em virtude dos aspectos analisados, notou-se a falta de compreensão e, até certo ponto, de distinção da prática atribuída à PCC e da prática desenvolvida no ES.

Em relação à categoria 'Dificuldades de implementação na formação inicial de professores', que tem 39,53\% das citações, percebe-se que a PCC exige para sua consolidação nas licenciaturas mudanças de concepções sobre o que é formação, currículo e prática. Assim, contradições emergem a medida que há dificuldades de romper com o modelo de formação docente da racionalidade técnica, o que tem como consequência a frágil articulação entre teoria e prática. Esse cenário se agrava nos resultados das pesquisas sobre a PCC quando as condições de trabalho e carreira dos professores formadores não são adequadas. Sendo assim, se apresentam as unidades de análise com menor incidência que compõe essa categoria.

Sobressai-se nos trabalhos que compõe a unidade de análise 'Condições de trabalho e carreira' a complexidade de desenvolver as atividades de PCC. Dessa forma, os trechos transcritos abaixo evidenciam que inserir a PCC em estruturas institucionais marcadas pelo modelo de formação docente da racionalidade técnica é um desafio, pois exige mudança de concepções de formação, currículo e prática e, consequentemente, uma mudança de cultura institucional marcada de visão do professor com um especialista. Portanto, os trechos abaixo destacam que em muitas instituições há necessidade de contratação de professores com formação na área de ensino, bem como, formações continuadas e espaços de planejamento coletivo para garantir a efetivação das atividades de PCC:

Dissertação 6: [...] ao longo dos anos na docência universitária, os docentes tiveram poucas oportunidades de participar de formações pedagógicas e para PCC. Percebe-se que os desafios encontrados para o desenvolvimento desse componente curricular parecem ser reforçados pelas condições de trabalho dos professores. Tese 8: Nas entrevistas identificaram-se fatores históricos e políticos anteriores às reformulações bem como disputas internas e consensos negociados na produção do currículo e as dificuldades na implantação da Prática como Componente Curricular. Entre as dificuldades estão a falta de professores com formação na área de ensino, não reconhecimento da didática da história como parte do campo da história, desvalorização da área de ensino dentro do curso, a não participação dos professores da área de ensino na definição do currículo.

Tese 13: [...] três grupos de sujeitos condicionam a melhoria da qualidade do curso ao compromisso e qualificação pedagógica do formador; contratação de docentes da área de Educação Química, visando à relação Química/Educação. 
Evento 12: [...] analisamos o perfil profissional dos 11 professores que atuam nas disciplinas dedicadas à PCC, caracterizando sua produção acadêmica e seu envolvimento com o Ensino de Biologia. Percebemos que a maioria (9) não possui relação com a educação escolar e a educação como área de pesquisa. Esse fato é preocupante, pois no caso dessas disciplinas deve-se trabalhar o processo de transposição didática, o que é dificultado se não se tiver experiência com a educação escolar e com a formação de professores.

Artigo 33: Além de reunir diferentes possibilidades de organização do componente curricular investigado e apresentar uma contextualização legal, a pesquisa revela que há falta de preparo dos formadores que ministram disciplinas que contemplam PCC.

Na unidade de análise 'Manutenção do modelo da racionalidade técnica' foram identificados 4 trabalhos, que representam 4,65\% do total. Esses trabalhos identificaram nos cursos analisados que, mesmo inserindo as atividades de PCC, não ocorreu uma mudança de concepção de formação de professores prevalecendo a segmentação entre os conhecimentos específicos e pedagógicos.

Entre as dificuldades para organizar nas licenciaturas as atividades de PCC, com menor incidência, tem-se a unidade de análise 'Dificuldade em promover a relação teoria-prática'. Esses três trabalhos identificados mostram que ao inserir a PCC no curso ocorreu um recuo da teoria em nome da prática. Dessa forma, esses cursos dão ênfase às atividades práticas e tem dificuldades em articulá-las ao conhecimento teórico. Cunha e Fernandes (2013), ao discutir as possibilidades da PCC para a formação de professores alertam que o deslocamento epistemológico do primado do científico para a supremacia da prática deve ser acompanhado de crítica, pois a valorização da prática pode fortalecer o desinvestimento no conhecimento e na intelectualização do professor. Ao mesmo tempo as autoras consideram que "[...] a inserção da Prática como Componente Curricular, assumida nas atuais diretrizes curriculares, pode fortalecer a recriação da relação teoria e prática" (CUNHA; FERNANDES; 2013, p. 54).

Por fim apenas um trabalho não encontrou a PCC ao analisar um curso de Educação Física. Nesse trabalho foram ouvidos estudantes e professores, sendo que os estudantes desconhecem totalmente a PCC, enquanto que os professores reconhecem sua ausência no curso e se mostram dispostos a implementá-la.

Ressalta-se outra importante lacuna nos resultados dos trabalhos analisados: estudos que compreendam as trajetórias de vida, formação e experiência na Educação Básica dos professores formadores e seus possíveis impactos no desenvolvimento de atividades de PCC. Nesse contexto considera-se que evidenciar quais são os elementos que constituem a PCC, a partir dessa perspectiva, pode auxiliar em formas de organizar propostas de formação continuada aos professores formadores. Insere-se nesses estudos a necessidade de abordar as relações entre conhecimentos específicos e pedagógicos, salientado as implicações dessas articulações para o desenvolvimento das atividades de PCC. 
Outra lacuna nos estudos sobre PCC são estudos sobre essas atividades em cursos na modalidade de Educação a Distância (EAD). Nos 129 trabalhos apenas 3 desenvolveram seus estudos sobre PCC em cursos ofertado nessa modalidade. Conforme pode ser visto nas citações abaixo, esses trabalhos têm como enfoque os cursos de Matemática, Química e Pedagogia e são, respectivamente, uma tese, uma dissertação e um artigo em evento:

Tese 2: Este trabalho se situa no campo de pesquisa da Educação Matemática, precisamente no estudo de cursos de formação inicial de professores de Matemática por meio da Educação a Distância (EAD). [...] este trabalho objetiva analisar como são incorporados os pressupostos da formação para a prática docente na escola básica - mais precisamente, como a Prática como Componente Curricular (PCC) é interpretada e integrada - e como se dá o uso das Tecnologias Digitais da Informação e Comunicação (TDIC) visando o ensino de matemática, no programa de um relevante curso de Licenciatura em Matemática na modalidade EAD online, oferecido por uma universidade federal que integra o consórcio Universidade Aberta do Brasil (UAB).

Dissertação 17: Este estudo se situa no campo das atuais políticas nacionais para a formação de professores de Química. O objetivo central é analisar como a Prática como Componente Curricular vem sendo entendida no currículo de dois cursos de Licenciatura em Química, identificando os sentidos mobilizados por ela. Os cursos são ofertados pela Universidade Federal de Mato Grosso (UFMT), campus central, na modalidade presencial, e pelo Instituto Federal de Mato Grosso (IFMT), oferecido na modalidade à distância, no contexto da Universidade Aberta do Brasil (UAB). Evento 10: Essa proposta visa apresentar a pesquisa sobre a formação inicial de professores surdos no Curso de Pedagogia, criado em uma perspectiva bilíngue, na modalidade online, inicialmente, com polos presenciais distribuídos por treze instituições no Brasil.

Isso posto, defende-se que as possibilidades da PCC nos cursos de licenciatura são fomentadas a partir de diferentes fatores, sendo necessário aprofundar nas análises, em trabalhos futuros, as relações entre as mudanças curriculares possibilitadas pela PCC e suas dificuldades de implementação com as efetivas condições de trabalho dos professores formadores, sendo essas condições de trabalho traduzidas em: salário, carreira, tempo de planejamento, formação continuada, etc.

Por fim, compreende-se a partir dos dados apresentados que os estudos sobre PCC nos 129 trabalhos analisados demonstram preocupação em discutir as potencialidades e dificuldades de inserir a PCC nos cursos de licenciatura. Isso significa a busca por consolidar a prática como uma dimensão do conhecimento que perpassa toda a formação do licenciando.

\section{CONSIDERAÇÕES FINAIS}

Este artigo apresentou como tema de investigação a Prática como Componente Curricular (PCC) na produção acadêmica do período de 2002 a 2018 . Diante desse tema, esse 
artigo propôs como objetivo analisar aspectos qualitativos e quantitativos da produção acadêmica sobre a PCC a partir de resumos de 129 trabalhos levantados e disponíveis em três bases de dados: Banco de Dissertações e Teses da Capes, Portal de Periódicos Capes e Google Acadêmico.

A análise dos resumos identificou os seguintes eixos: áreas das licenciaturas foco de cada estudo, o ano de sua defesa e lou publicação, o programa e universidade em que foram realizados, as revistas e eventos de publicação, os objetivos da pesquisa, a metodologia utilizada e os principais resultados.

Dessa forma, a partir da análise dos aspectos qualitativos e quantitativos da produção acadêmica sobre a PCC a partir de resumos de 129 trabalhos foi possível verificar que algumas áreas específicas precisam fomentar estudos sobre a PCC em suas licenciaturas. Destaca-se a ausência de estudos sobre a PCC nas licenciaturas em Ciências, Filosofia, Física, História, Letras e Pedagogia.

Com relação às metodologias utilizadas nos estudos analisados, destaca-se que poucos trabalhos desenvolvem abordagem etnográfica e/ou de observação participante em seus estudos demonstrando que essa é uma lacuna metodológica. Portanto, muitos estudos apresentam as atividades de PCC desenvolvidas nas licenciaturas, mas a partir de entrevistas e questionários.

Por sua vez, a análise dos principais resultados das pesquisas analisadas ressaltou duas lacunas nos estudos sobre a PCC que podem ser pesquisadas de forma separada ou em articulação: as condições de trabalho e carreira dos professores formadores e as trajetórias de vida, de formação e de experiência na Educação Básica. Ainda se destaca que poucos estudos foram realizados em cursos na modalidade EAD.

Por fim, compreende-se a partir da análise realizada sobre a PCC nos 129 trabalhos, que há muitas lacunas nos estudos. Entretanto, o número de trabalhos e seu crescimento ao longo dos anos, juntamente com a nova resolução para a formação docente de 2015, demonstram que a PCC está em processo de consolidação da prática como uma dimensão do conhecimento que perpassa toda a formação do licenciando. 


\section{REFERÊNCIAS}

BRASIL. Decreto-Lei n. 1.190, de 04 de abril de 1939 (1939). Dá organização à Faculdade Nacional de Filosofia. Diário Oficial da União. Rio de Janeiro, RJ: Ministério da Educação e Saúde Pública, 1939.

. Parecer n. 09 de 2001. Diretrizes Curriculares Nacionais para a formação de Professores da Educação Básica, em nível superior, curso de licenciatura, de graduação plena. Diário Oficial da União. Brasília, DF: Ministério da Educação, 2001a.

Parecer n. 28 de 2001. Dá nova redação ao Parecer CNE/CP 21/2001, que estabelece a duração e a carga horária dos cursos de Formação de Professores da Educação Básica, em nível superior, curso de licenciatura, de graduação plena. Diário Oficial da União. Brasília, DF: Ministério da Educação, 2001b.

. Resolução n. 01 de 2002. Institui Diretrizes Curriculares Nacionais para a Formação de Professores da Educação Básica, em nível superior, curso de licenciatura, de graduação plena. Diário Oficial da União. Brasília, DF: Ministério da Educação, 2002a.

Resolução n.02 de 2002. Institui a duração e a carga horária dos cursos de licenciatura, de graduação plena, de formação de professores da Educação Básica em nível superior. Diário Oficial da União. Brasília, DF: Ministério da Educação, 2002b.

Parecer n. 15 de 2005. Solicitação de esclarecimento sobre as Resoluções CNE/CP $n^{\circ}$ s 1/2002, que institui Diretrizes Curriculares Nacionais para a Formação de Professores da Educação Básica, em nível superior, curso de licenciatura, de graduação plena, e 2/2002, que institui a duração e a carga horária dos cursos de licenciatura, de graduação plena, de Formação de Professores da Educação Básica, em nível superior. Diário Oficial da União. Brasília, DF: Ministério da Educação, 2005.

.Resolução n.02 de 2015. Define as Diretrizes Curriculares Nacionais para a formação inicial em nível superior (cursos de licenciatura, cursos de formação pedagógica para graduados e cursos de segunda licenciatura) e para a formação continuada. Diário Oficial da União. Brasília, DF: Ministério da Educação, 2015.

CUNHA, M. I. O tema da formação de professores: trajetórias e tendências do campo na pesquisa e na ação. Revista Educação e Pesquisa, v.39, n.3, p.609-624, 2013.

FERNANDES, C.M.B.; CUNHA, M. I. Formação de professores: tensão entre discursos, políticas teorias e práticas. Revista Inter-Ação, v. 38, n. 1, p. 51-65, jan./abr. 2013.

Disponível em: < https://www.revistas.ufg.br/interacao/article/view/25127/15119 >. Acesso em: 25 maio. 2018.

MARCELO, C. G. Pesquisa sobre formação de professores: o conhecimento sobre aprender a ensinar. Revista Brasileira de Educação, nº 9, p. 51-75, 1998.

TEIXEIRA, P. M. M. MEGID NETO, J. A Produção Acadêmica em Ensino de Biologia no Brasil - 40 anos (1972-2011): Base Institucional e Tendências Temáticas e Metodológicas. Revista Brasileira de Pesquisa em Educação em Ciências (RBPEC), v. 17, n.2, p. 521-549, ago, 2017. 
MINAYO, M.C.S. Pesquisa social: teoria, método e criatividade. Petrópolis: Vozes, 2015.

MOHR \& H.G. WIELEWICKI. (Org.) Prática como componente curricular: que novidade é essa 15 anos depois? Florianópolis: NUP/CED/UFSC. 2017.

REAL, G. C. M. Prática como Componente Curricular: o que isso significa na prática? Educação e Fronteiras On-Line. v. 2, n.5, p.48-62, 2012.

ROMANOWSKI, J. P; ENS, R. T. As pesquisas denominadas do tipo "estado da arte" em educação. Revista Diálogo Educacional. Curitiba, v. 6, n.19, p.37-50, set./dez. 2006.

SAVIANI, D. Formação de professores: aspectos históricos e teóricos no contexto brasileiro. Revista Brasileira de Educação, v. 14, n.40, p.143-145, 2009. 